\title{
Speed and actual distances travelled by radiocollared wolves in Białowieża Primeval Forest (Poland)
}

\author{
Marco MUSIANI ${ }^{1}$, Henryk OKARMA ${ }^{2}$ and Włodzimierz JĘDRZEJEWSKI ${ }^{3}$
}

\begin{abstract}
Musiani M., Okarma H. and Jędrzejewski W. 1998. Speed and actual distances travelled by radiocollared wolves in Białowieża Primeval Forest (Poland). Acta Theriologica 43: 409-416.
\end{abstract}

The relationship between the straight line distances (SLD), obtained from telemetry locations, and actual distances travelled by wolves Canis lupus (ADT), measured by snowtracking, was investigated in Białowieża Primeval Forest, E Poland, in winter 1995/96. Radiolocations determined at 15-min time intervals approximated the ADT by wolves reasonably well. If wolves were relocated at $0.5-$ to 2 -h intervals, SLD can be multiplied by a correction factor of 1.3 to obtain ADT. Within the range of SLD from 1 to $10 \mathrm{~km}$, they could also be converted into ADT using a regression equation: $\mathrm{ADT}=0.34+1.19(\mathrm{SLD})$, with standard errors of prediction \pm 0.13 to $\pm 0.3 \mathrm{~km}$. The average travelling speed of wolves was $3.78 \mathrm{~km} / \mathrm{h}$ (SD 1.23, range 1.6-6.1 km). Wolves walking the forest trails, roads and frozen rivers moved significantly faster than in the forest. Also, individuals travelling with other pack members moved faster than those walking singly.

Department of Evolutionary Biology, Ethology and Behavioural Ecology Group, University of Siena, Via Mattioli 4, 53100 Siena, Italy (MM); Mammal Research Institute, Polish Academy of Sciences, 17-230 Białowieża, Poland (HO, WJ)

Key words: Canis lupus, radiotracking, movements, snowtracking, travel speed

\section{Introduction}

Straight-line distances (SLD) between consecutive locations of radiocollared wolves Canis lupus often have been used to describe their movements (Mech 1970, 1994, Mech et al. 1971, Fritts and Mech 1981, Messier 1985, Fuller 1989, 1991). However, the SLD reflect the actual distances travelled (ADT) only in some situations, such as when an animal moves along a straight road. Thus, SLD data approximate the minimum rather than real distances covered by an animal. So

\footnotetext{
${ }^{1}$ Present address: Faculty of Environmental Design, University of Calgary, 2500 University Drive NW, Calgary, Alberta T2N 1N4, Canada

${ }^{2}$ Present address: Institute of Nature Conservation, Polish Academy of Sciences, Lubicz 46, 31-512 Kraków, Poland

${ }^{3}$ Reprint requests to W. Jędrzejewski; e-mail: wlodek@bison.zbs.bialowieza.pl
} 
far, the only data on speed of wolves during their regular travel are available for individuals moving in open areas, namely on a frozen lake or barren ground (Mech 1970, 1994).

The aims of this study, conducted in the winter of 1995/96, were to: (1) investigate the relation between straight-line distances (SLD) covered by moving wolves as measured by radiotelemetry and actual distances travelled (ADT) measured during subsequent snowtracking, and (2) estimate the speed of moving wolves. We attempted to quantify the factors affecting variation in wolf speed and obtain the correction factors that could be applied to telemetry data to calculate ADT by radiotracked wolves. The study was part of a long-term project on wolf-ungulate relationships in the pristine temperate forests of Białowieża, E Poland (Jędrzejewski et al. 1992, in press, Jędrzejewska et al. 1996, 1997, Okarma et al. 1998).

\section{Study area}

Due to centuries-long protection as a hunting ground of Polish kings, Lithuanian dukes, and Russian czars, Białowieża Primeval Forest ( $=\mathrm{BPF}, 1451 \mathrm{~km}^{2}, 52^{\circ} 30^{\prime}-53^{\circ} \mathrm{N}, 23^{\circ} 30^{\prime}-24^{\circ} 15^{\prime} \mathrm{E}$ ) is one of the best preserved forest ecosystems in the lowlands of temperate Europe (details in Jędrzejewska $e t$ al. 1996). It is located on the Polish-Belarussian borderland and is composed of mixed and deciduous stands with spruce Picea abies, pine Pinus silvestris, oak Quercus robur, hornbeam Carpinus betulus, black alder Alnus glutinosa, ash Fraxinus excelsior, lime Tilia cordata, and maple Acer platanoides. Most of the Polish part of BPF $\left(530 \mathrm{~km}^{2}\right)$ is a commercial forest exploited for timber and undergoing game management. The remaining portion of the Polish part $\left(47 \mathrm{~km}^{2}\right)$ has been strictly protected since 1921 as Białowieża National Park, where neither timber exploitation nor hunting is allowed. In July 1996, the Park was enlarged to cover $100 \mathrm{~km}^{2}$.

BPF harbours a rich community of ungulates: European bison Bison bonasus, moose Alces alces, red deer Cervus elaphus, roe deer Capreolus capreolus, and wild boar Sus scrofa coexist there with two species of large predators, the wolf and the lynx Lynx lynx. Since 1989, wolves have been protected in the Polish part of BPF, whereas they are hunted in the Belarussian part (Jędrzejewska et al. 1996).

The climate of BPF is transitional, but continental features prevail. The mean January temperature in 1996 was $-8.5^{\circ} \mathrm{C}$.

\section{Material and methods}

Four wolves ( 2 adult females, 1 subadult female, and 1 young female) from two packs of 5-7 animals each were captured and fitted with radiocollars in 1994-1996 in the Polish part of BPF (see Okarma and Jędrzejewski 1997, Okarma et al. 1998 for details). The data presented here were collected in winter 1995/96 during several sessions of continuous (1 to 5 -day) radiotracking. We obtained radiolocations from the ground by driving a car on forest roads. We tried to stay $>300 \mathrm{~m}$ from the monitored animal to avoid influencing its movement and $<1000 \mathrm{~m}$ away to obtain accurate locations. There was no indication that movements of wolves were affected by our presence. We estimate that the average error of radiolocations of moving wolves was about $300 \mathrm{~m}$. For mapping the locations of wolves, we used forest maps with a grid of $533 \times 533 \mathrm{~m}$ squares (forest compartments), into which BPF is divided for forestry practices. Depending on the estimated location of wolves, their 


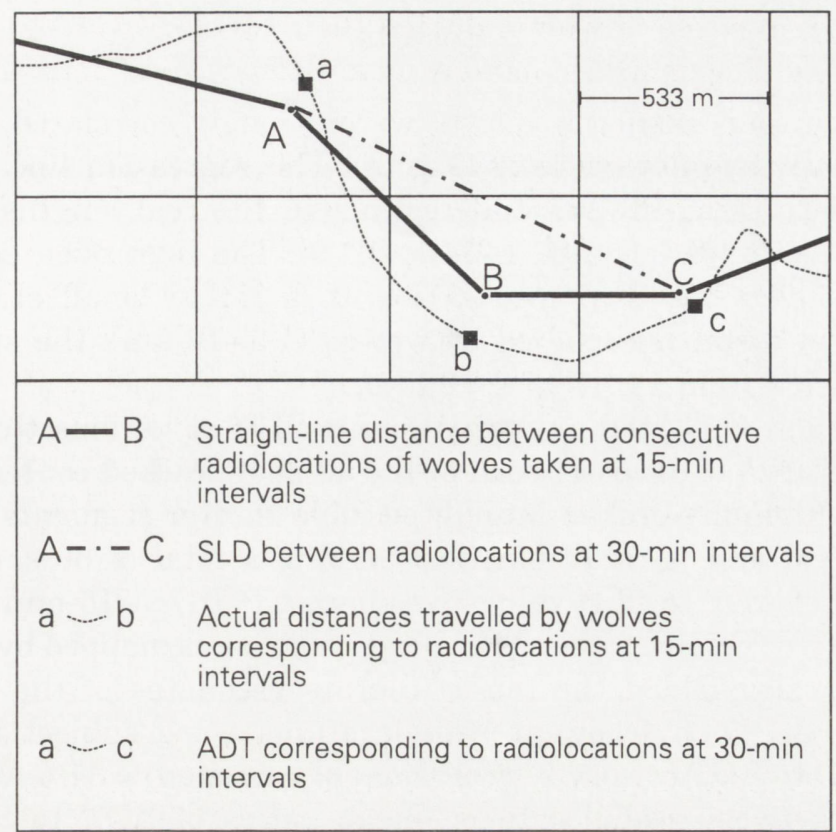

Fig. 1. Scheme of distances covered by wolves as sampled by radiotelemetry and snowtracking. The wolves tracks on snow (dotted line) were followed step by step between consecutive telemetry locations (A, B, and C). Starting and ending points of actual distances travelled by wolves (a, b, and c) were arbitrarily fixed on the wolves' route at half-way between two sides of the grid squares which were crossed by the radiotracked animals.

position was mapped as in the centre of a forest compartment, in the middle of a side of two adjacent squares, or in the corner between four adjacent squares. This method of mapping caused an additional error of wolf location averaging $67 \mathrm{~m}$ (maximally $133 \mathrm{~m}$ ). Such locations were then converted into co-ordinates for further calculations. The shortest interval between two locations was 15 minutes. This was the minimum time needed to take the bearings, record time and location, and reach a new position.

Usually on the day following the night of radiotracking, the wolves' tracks on snow were followed step by step between every two telemetry locations. Starting and ending points of ADT were arbitrarily fixed on the wolves' route at half-way between two sides of a grid square, which was crossed by the tracked animal (Fig. 1). The length of each travel segment (ADT) was measured by pacing. Pace length depended on snow depth and averaged $0.68 \mathrm{~m}$ (SD 0.14). During the study, snow cover varied from 5 to $17 \mathrm{~cm}$, ie it never exceeded $40 \mathrm{~cm}$, the threshold beyond which the wolf's movements are impeded (Kelsall 1969, Mech 1970). Characteristics of the routes used by wolves were recorded during each session. Group size ( 1 or $\geq 2$ wolves) was determined by counting any branching of their tracks. The routes travelled were arbitrarily classified as 'forest', 'trails and roads', and 'frozen rivers' when $>80 \%$ of the track length was confined to one of these substrates. A total of 13 travel segments were measured by both radiotracking and snowtracking. They represented 30 to 120 -min long movements as recorded by radiotracking and corresponded to 1.5 to $11.9-\mathrm{km}$ travels of wolves as measured during snowtracking (totally $70.07 \mathrm{~km}$ of snowtracking). Data on snow depth and temperature were provided by the Białowieża meteorological station. 


\section{Results}

The SLD from our telemetry efforts were strongly correlated with the ADT measures obtained by snowtracking (Fig. 2). The regression line lies above the $x=y$ line. Radiotracking always underestimated the real lengths of wolf movements, on average by $21 \%$ (range $1-34 \%$, SD 9). The regression equation makes it possible to convert the SLD into $\mathrm{ADT}$ with a rather small error; within the recorded range of distances covered by wolves $(1.5-12 \mathrm{~km})$, the standard errors of prediction varied from \pm 0.13 to $\pm 0.30 \mathrm{~km}$.

We checked how the ADT compares to our SLD at various time intervals of radiolocations. For that purpose, each of the 13 snowtracked routes was taken as a whole and additionally broken into all possible shorter segments corresponding to 15-min interval and its multiplicities, making a total of 60 samples (Fig. 3). The mean ratio of ADT to SLD values was lowest (1.01) at 15-min time intervals between successive radiolocations. Therefore, wolf routes mapped by radiolocations at 15-min intervals yielded the most accurate estimates of the real distances covered. However, such frequent radiolocations were subject to the largest variation in SLD to ADT ratio, CV (coefficient of variation) $=37 \%$. With increasing time intervals between radiolocations, mean ratios of ADT to SLD grew and reached a plateau at 30-120 min (Fig. 3). Mean ADT/SLD ratios for radiolocations taken at 30 to 120 -min intervals were from 1.28 to 1.43 (1.3 on average). Also,

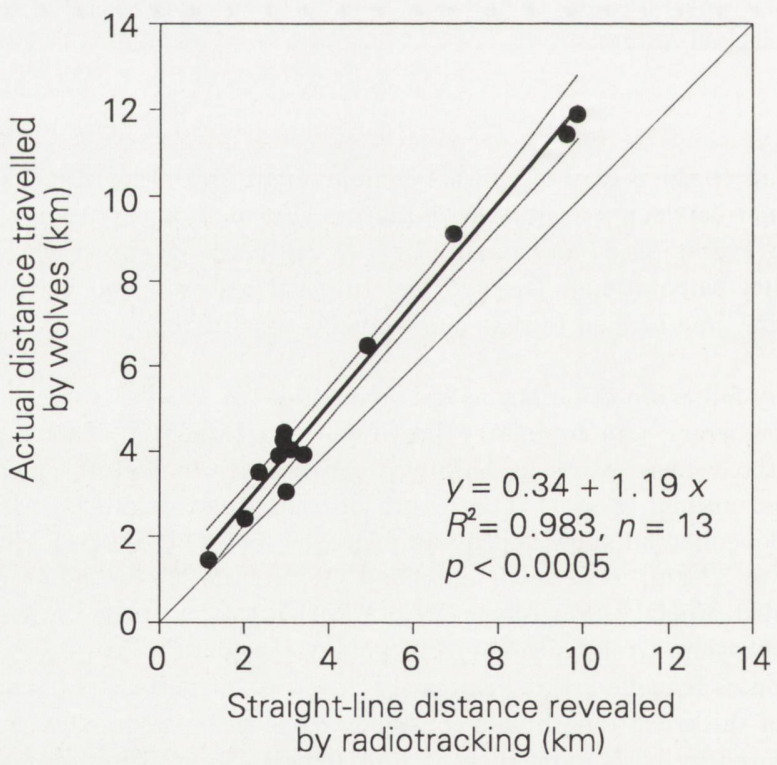

Fig. 2. Relationship between straight-line distances covered by wolves (estimated by radiotelemetry) and actual distances travelled (measured during successive snowtracking) for 13 routes of wolves in Białowieża Primeval Forest, winter 1995/96. 


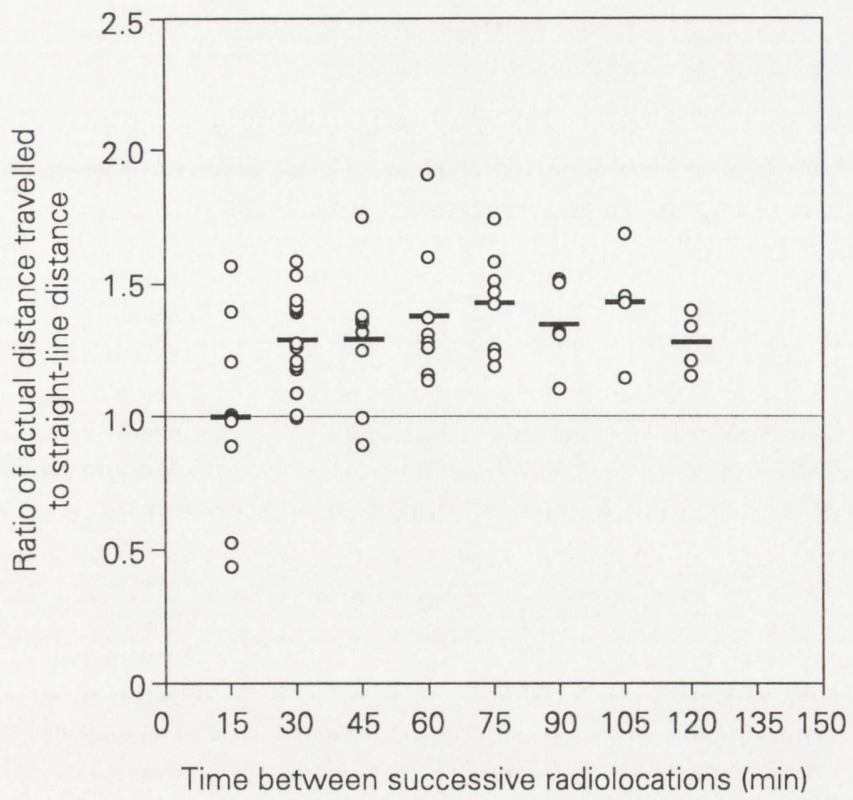

Fig. 3. Ratios of snowtracked ADT to telemetry SLD in wolf movements in relation to time intervals (15-min and its multiplicities) between successive radiolocations. For this presentation, data for 13 routes covered by both radio- and snowtracking were broken into all possible shorter time intervals. Bars are mean values.

variation around mean values was much lower, CV from 9 to $20 \%$. Hence, a correction factor of 1.3 can be applied to SLD obtained by our telemetry method to estimate $\mathrm{ADT}$ of wolves.

The 13 snowtracked routes included 3 cases of wolves travelling in forest trails and roads, 3 on frozen rivers, 5 in the forest, and 2 routes located partly on roads and partly in the forest. Five snowtracking samples were of wolves travelling with other members of the pack and 8 of wolves moving alone. The speed of wolves varied from 1.61 to $6.10 \mathrm{~km} / \mathrm{h}$, mean $3.78 \mathrm{~km} / \mathrm{h}$, SD 1.23 (Table 1). Wolves travelling on trails, roads and frozen rivers moved significantly faster (mean 4.7 $\mathrm{km} / \mathrm{h}$, SD 0.97) than in the forest (mean $3.0 \mathrm{~km} / \mathrm{h}$, SD $0.86 ; t=3.545$, df $=13$, $p=0.004$ ). Also, when travelling in a pack, wolves moved notably faster (mean $4.8 \mathrm{~km} / \mathrm{h}$, SD 1.06) than in cases of moving singly (mean $3.1 \mathrm{~km} / \mathrm{h}$, SD $0.82 ; t=$ $3.493 \mathrm{df}=13, p=0.004$ ). Moreover, the same pattern (slower pace when moving in the forest) was apparent in both packs and single wolves (Table 1). Indeed, these two factors (substrate and pack/single) explained $74 \%$ of the observed variation in the speed of wolves moving in BPF (ANOVA, $F=10.1, p=0.009$ for substrate and $F=9.9, p=0.009$ for pack factor). Within the observed range of snow depth $(5-17 \mathrm{~cm})$, snow did not affect the wolves' speed $\left(R^{2}=0.02, \mathrm{df}=13\right.$, $p>0.6$ ). 
Table 1. Speed of wolves moving in winter 1995/96 in Białowieża Primeval Forest (E Poland) as determined by radiotracking and subsequent snowtracking.

\begin{tabular}{|c|c|c|c|c|c|}
\hline \multirow{2}{*}{ Date } & \multirow{2}{*}{ Hours } & \multicolumn{2}{|c|}{ Speed $(\mathrm{km} / \mathrm{h})$} & \multirow{2}{*}{ Substrate } & \multirow{2}{*}{$\begin{array}{l}\text { Snow depth } \\
\quad(\mathrm{cm})\end{array}$} \\
\hline & & Single wolves & Groups $\geq 2$ inds & & \\
\hline Nov 22,1995 & $0530-0730$ & & 5.96 & Trail and road & 5 \\
\hline Dec 19,1995 & $0915-1045$ & 1.61 & & Forest & 9 \\
\hline \multirow[t]{2}{*}{ Jan 4, 1996} & $1030-1230$ & & 4.70 & Trail and road & 12 \\
\hline & & & 4.53 & Forest & 12 \\
\hline Jan 7, 1996 & $1715-1830$ & 3.56 & & Forest & 12 \\
\hline \multirow[t]{2}{*}{ Jan 15, 1996} & $0615-0815$ & 4.02 & & Trail and road & 11 \\
\hline & & 2.49 & & Forest & 11 \\
\hline Jan 18, 1996 & $1000-1130$ & 2.70 & & Forest & 12 \\
\hline Jan 20, 1996 & $2145-2215$ & 2.90 & & Forest & 12 \\
\hline Jan 29, 1996 & $0645-0800$ & 2.81 & & Forest & 13 \\
\hline Jan 30, 1996 & $0530-0630$ & 3.91 & & Frozen river & 13 \\
\hline Jan 31, 1996 & $0030-0130$ & 3.96 & & Frozen river & 13 \\
\hline Feb 1, 1996 & $0430-0500$ & & 6.10 & Frozen river & 13 \\
\hline Feb 12, 1996 & $2230-2345$ & & 3.42 & Forest & 17 \\
\hline Feb 14, 1996 & $1915-2115$ & & 4.05 & Trail and road & 17 \\
\hline
\end{tabular}

Mean values (SD)

$\begin{array}{lll}\text { Forest } & 2.7(0.64) & 4.0(0.78) \\ \text { Trail, road, and frozen river } & 4.0(0.06) & 5.2(0.99)\end{array}$

Total

\section{Discussion}

According to Breitenmoser et al. (1992), the best way to evaluate the real distances covered by a radiocollared animal would be to track it parallel to a continuous radiolocation series, and compare the accumulated SLD with the real distance travelled in order to obtain a correction factor. We did that for wolves living in the dense temperate forests of Białowieża. We concluded that: (1) if wolves are radiolocated at 15-min intervals, the summed straight-line distances between radiolocations are good enough approximation of the actual distance travelled, given that the sample of radiolocations is large; (2) if wolves are radiolocated at 0.5 to 2 -h intervals, the correction factor of 1.3 should be applied to SLD; and (3) within the range of $1-10 \mathrm{~km}$, SLD can also be converted to ADT based on regression between those two estimates. Although this project was done in winter, the conditions were fairly mild and snow did not affect wolves activity. Thus, we think that the results are applicable to other seasons of the year, as well.

The proposed method for estimating ADT of wolves has its limitations. First, as a measure of the total movement activity of wolves, it is still an underestimate, 
because we snowtracked directional movements of wolves and not the cases of their spatially concentrated bustling, eg around resting site or prey killed. Secondly, the conversion proposed here cannot be applied to data obtained by radiolocating wolves at intervals longer than a few hours.

The speed of wolves recorded by us $(1.6-6.1 \mathrm{~km} / \mathrm{h})$ is lower than those reported for wolves travelling on the tundra $(8.7 \mathrm{~km} / \mathrm{h})$ and the iced surface of a lake $(8$ $\mathrm{km} / \mathrm{h}$ ) (Mech 1970, 1994). Mech observed the wolves directly, whereas we radiotracked and subsequently snowtracked them, so our results included situations when they might have paused or stopped for a short time. Furthermore, the wolves observed by Mech were travelling in the open terrain. In BPF, wolves also moved significantly faster on frozen rivers and forest roads than in the forest proper. The slower pace of wolves moving singly, as documented in this study, may be a result of greater vigilance and caution of wolves which temporarily broke away from their packs or different activites (eg searching).

Acknowledgements: We thank S. Śnieżko for his help during snowtracking, Dr Z. Pucek for his advice and suggestions, Drs S. Lovari and B. Jędrzejewska for helpful comments on the manuscript. K. Zub drew the figures. This study was financed by the KBN project 6P20401905. M. Musiani made use of a Goverment of Poland Award obtained through the Italian Ministry of Foreign Affairs.

\section{References}

Breitenmoser U., Breitenmoser-Wursten C., Zuleta G. A., Bernhart F. and O'Donoghue M. 1992. A method for estimate travel distances of fast moving animals. Biotelemetry XII, Aug. 31 - Sep. 5, 1992, Ancona, Italy.

Fritts S. H. and Mech L. D. 1981. Dynamics, movements, and feeding ecology of a newly-protected wolf population in northwestern Minnesota. Wildlife Monographs 80: 1-80.

Fuller T. K. 1989. Population dynamics of wolves in north-central Minnesota. Wildlife Monographs 105: 1-41.

Fuller T. K. 1991. Effect of snow depth on wolf activity and prey selection in north central Minnesota. Canadian Journal of Zoology 69: 283-287.

Jędrzejewska B., Jędrzejewski W., Bunevich A. N., Miłkowski L. and Krasiński Z. A. 1997. Factors shaping population densitites and increase rates of ungulates in Białowieża Primeval Forest (Poland and Belarus) in the 19th and 20th centuries. Acta Theriologica 42: 399-451.

Jędrzejewska B., Jędrzejewski W., Bunevich A. N., Miłkowski L. and Okarma H. 1996. Population dynamics of wolves Canis lupus in Białowieża Primeval Forest (Poland and Belarus) in relation to hunting by humans, 1847-1993. Mammal Review 26: 103-126.

Jędrzejewski W., Jędrzejewska B., Okarma H. and Ruprecht A. L. 1992. Wolf predation and snow cover as mortality factors in the ungulate community of the Białowieża National Park, Poland. Oecologia 90: 27-36.

Kelsall J. P. 1969. Structural adaptations of moose and deer for snow. Journal of Mammalogy 50: 302-310.

Mech L. D. 1970. The wolf: ecology and behavior of an endangered species. Natural History Press, New York: 1-389.

Mech L. D. 1994. Regular and homeward travel speeds of Arctic wolves. Journal of Mammalogy 75 : $741-742$. 
Mech L. D., Frenzel L. D. Jr, Ream R. R. and Winship J. W. 1971. Movements, behavior, and ecology of timber wolves in Northeastern Minnesota. [In: Ecological studies of the timber wolf in northeastern Minnesota. Mech L. D. and Frenzel L. D. Jr, eds]. USDA Forest Service Research Paper NC-52: 1-34.

Messier F. 1985. Solitary living and extraterritorial movements of wolves in relation to social status and prey abundance. Canadian Journal of Zoology 63: 239-245.

Okarma H. and Jędrzejewski W. 1997. Livetrapping wolves with nets. Wildlife Society Bulletin 25: $78-82$.

Okarma H., Jędrzejewski W., Schmidt K., Śnieżko S., Bunevich A. N. and Jędrzejewska B. 1998. Home ranges of wolves in Białowieża Primeval Forest, Poland, compared with other Eurasian populations. Journal of Mammalogy 79: 842-852.

Received 29 April 1998, accepted 27 October 1998. 